\title{
A Grammatical Approach for Customization of Laminated Composite Materials
}

\author{
Soumitra Nandi, ${ }^{*}$ Zahed Siddique and M. Cengiz Altan \\ School of AME, University of Oklahoma, Norman, OK 73019, USA
}

\begin{abstract}
The wide range of properties covered by the manufacturable fiber-matrix combinations of composite materials, along with their directional property characteristics, provides designers with material selection flexibility during designing composite material products. Meeting multiple property goals, however, complicates the design process as both the composite material selection and the component shape formation becomes intricate with the multiple loading conditions, which may require matrix calculations of high order to determine theoretical value of composite material properties. This article presents a grammatical approach that is derived by extending shape grammars to simultaneously consider the shape of a component and select appropriate composite materials to meet multiple property goals, derived from a set of design loads. In this approach the grammar is divided into four interconnected steps, which are used to design the shape of the component depending on its function and user requirements, calculate the property requirements from the loading constraints based on the designed shape, and select composite materials according to the property requirements. Selection of composite materials involves determining the fiber and matrix, their volume fraction, number of plies, and ply orientations in different location of the load-bearing component. A hollow shape hip replacement joint is designed using composite material to illustrate the approach. Finite element analysis is performed to verify the design.
\end{abstract}

Key Words: laminate customization, integrate material and shape design, shape grammar, laminate design, composite material design.

\section{Introduction}

The concept of composite material involve combining two or more materials to achieve a unique set of properties, when none of the individual materials posses all the required properties. One of the advantages of using composite materials over the conventional engineering materials (metals) is the ability to manipulate their directional properties. Designers utilize different characteristics of composite materials to achieve several design goals, which might include reducing weight, increasing designed life of engineering components, reducing costs of production, maximizing reliability, ensuring safety of rotational structures, etc. However, existing material selection approaches for the isotropic material design are not readily applicable for the design of orthotropic composite materials. Consequently, there is a need to develop an approach to design load-bearing components using laminated composite materials.

The concept of shape grammar, originated from architecture, can simplify the overall design process and offer the ability to explore a vast range of design options [1]. This can be used to simplify the design of composite material products with nonuniform shapes

*Author to whom correspondence should be addressed.

E-mail: Soumitra.Nandi@ou.edu

Figures $1-5$ and $7-15$ appear in color online: http://cer.sagepub.com that will carry multiple types of loads, where the shape and loads together define the directional property requirements at different locations of the component. Shape grammar defines a set of shape transformation rules called a language. In the language, any shape can be derived through the application of the rules defined by the grammar. In engineering, shape grammar has been used to create a shape of component with desired specifications and to compare them with the capabilities of a traditional production system [2-4]. Shape grammar has been extensively used in modern $2 \mathrm{D}$ and $3 \mathrm{D}$ architectural design [5-7]. Shape grammar approach is used to design structure and shape of products (especially consumer products such as coffee makers, telephones, toasters, and flashlights) [1]. The design is carried out in two basic phases; the Functional Design Phase and the Form Design Phase. Thus shape grammar has the ability to generate a wide variety of designs involving complicated shapes [8-10].

Researchers have used shape grammar in production system and engineering design. Shape grammar has been defined as a language of constructive solid geometry and boundary representations. Parametric shape grammar has been developed to generate optimal truss structures [11-13]. It has also been shown that shape grammar can be employed with a preference function (Multi-agent Shape Grammar) [14] or other techniques (such as Cellular Automata) [15] to derive self-generative rules to achieve an intended system behavior. The use of shape 
grammar was extended for designing individual products while capturing brand identity; cost expressions were also associated with the grammar rules $[4,16]$.

Shape grammar has not been used to design loadbearing components using composite materials. Rather, different types of optimization and finite element methods have been employed to design and analyze shape and structure of composite material products [1725] simultaneously considering manufacturing processes [26,27]. In this research, a grammatical approach is defined that incorporates composite material selection and laminate design with a shape grammar to generate customized shape and meet multiple directional properties throughout the component.

Load-bearing components usually perform more than one function. They may carry bending moments, withstand very high or very low pressure, transmit heat and electricity, provide resistance to corrosion, etc. On the other hand, the designer has one or more goals to achieve during the design, such as to make the engineering component as cheap, light, or safe, as possible. Selection of appropriate material is the first step to achieve all these functions and goals. In the traditional approach [28-31] material selection involves choosing material with a single and specific property limit. This approach is not appropriate for composite material selection of complex design problems. In the work presented in this article, the selection of material is performed using the 'Composite material selection tool' [32]. The selection of composite material is also intertwined with the shape and the loading constraints. To validate the design in the example, a finite element analysis tool, Patran (Nastran enabled), is used to analyze stresses and strains at different layers of the designed component under given loading constrains.

\section{Overall Approach}

The work presented in this article focuses on extending shape grammar in a composite material customization approach. The proposed approach is divided into four phases: (i) Functional Design Phase, (ii) Form Design Phase, (iii) Material and Loading Design Phase, and (iv) Laminate Design Phase. The flow of activities in the different phases of the approach is also shown in Figure 1. The generation of the initial shape takes place in the Functional Design Phase, which begins with geometric entities. Functional requirements, such as types and location of design loads, are addressed by the application of a set of rules defined in the grammar. The Form Design Phase is performed using a

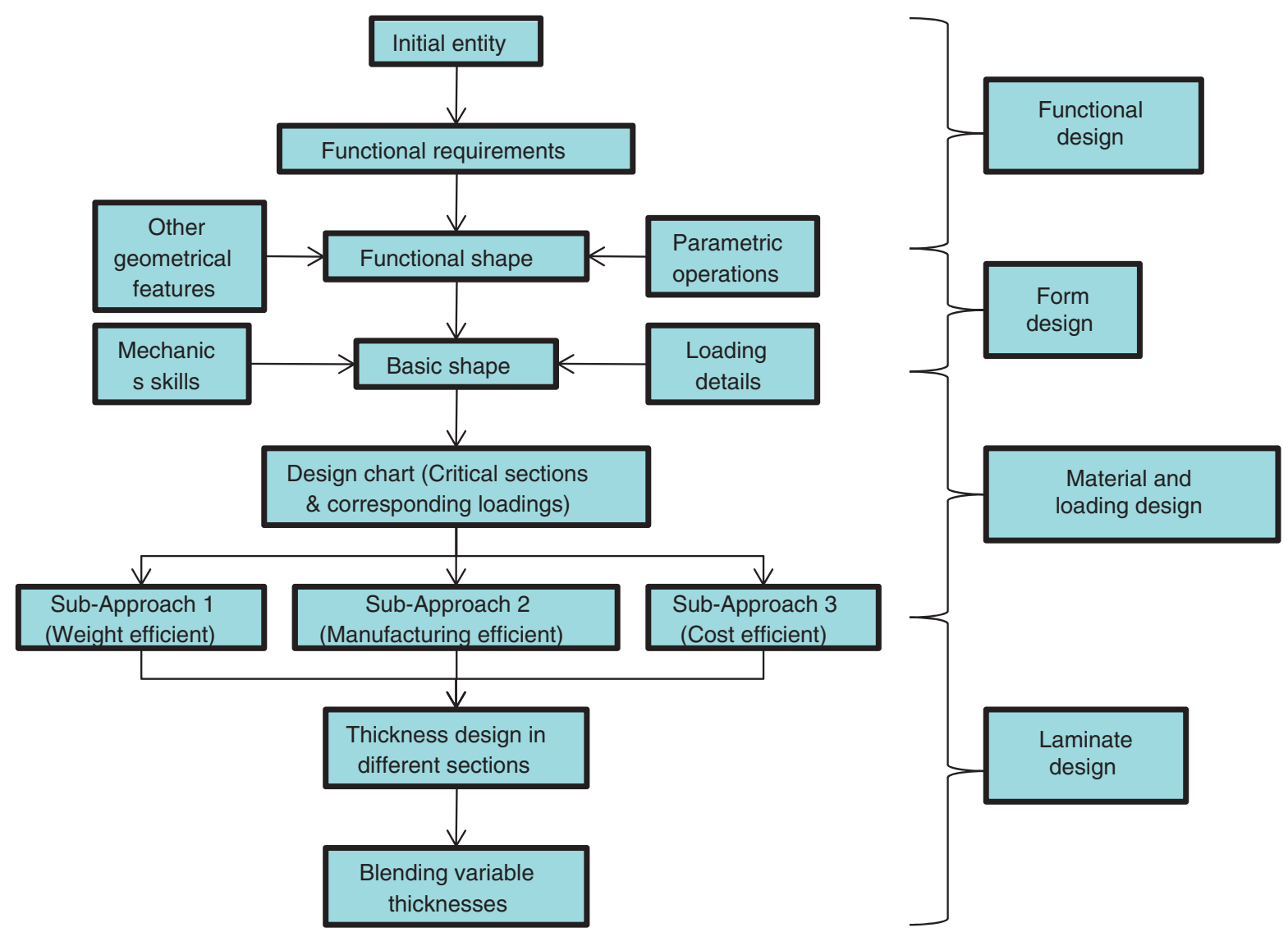

Figure 1. Overall approach. 
number of additions or subtractions of different geometric features to the initial entity to generate the basic shape. These geometric feature operations can be defined by a set of rules using shape grammar technique. Thus, generated basic shape may be the inner shape or the outer shape of a component body, which is specified in the design requirements. In the Material and Loading Design Phase, the loading details are defined as additional rules in the generated shape grammar to create a design chart that calculates the directional property requirements at different cross-sections of the body. Basic knowledge in mechanics is used to define the rules at this stage of the grammar to determine the possible critical sections of the loaded component.

Depending on the property requirements at different cross-sections of the component, the composite material is specified. The composite material selection and customization can be performed in one of three different sub-approaches (Figure 1). All these sub-approaches use the composite material customization tool [32] to select appropriate composite material for different locations of the component. The method of selection used in the tool is explained in Section 4.4. The Laminate Design Phase is interrelated with the above mentioned subapproaches, which are explained in Sections 2.1, 2.2, and 2.3. In this phase, number of plies in each laminate, their orientation, and blending of variable thicknesses to avoid stress concentration are analyzed.

\subsection{Sub-Approach 1: Weight Efficient}

The first sub-approach is based with a view to reduce the weight of the component as much as possible (see Figure 2 for the steps). It is probable that this approach

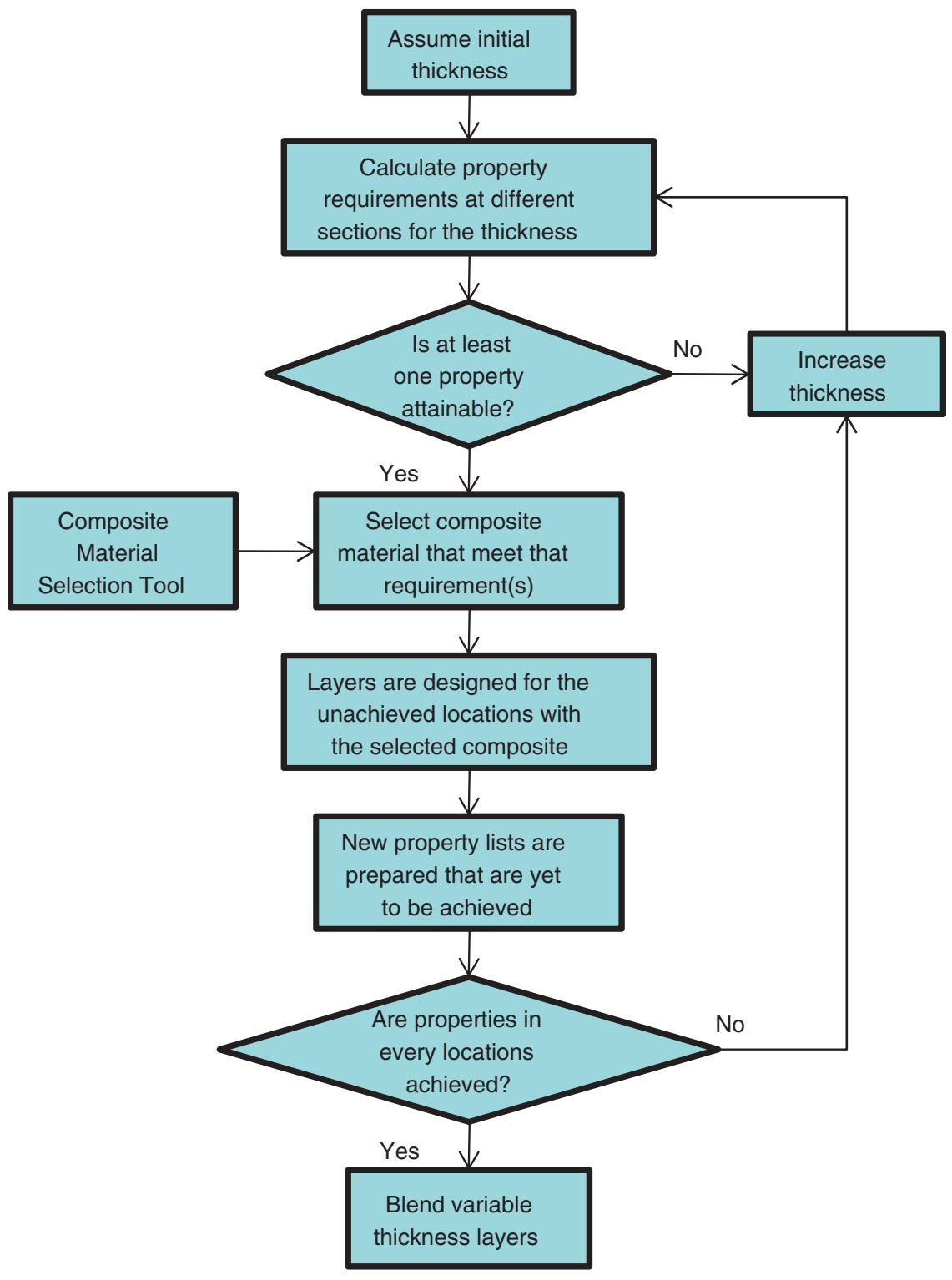

Figure 2. Sub-Approach 1 (weight efficient method). 


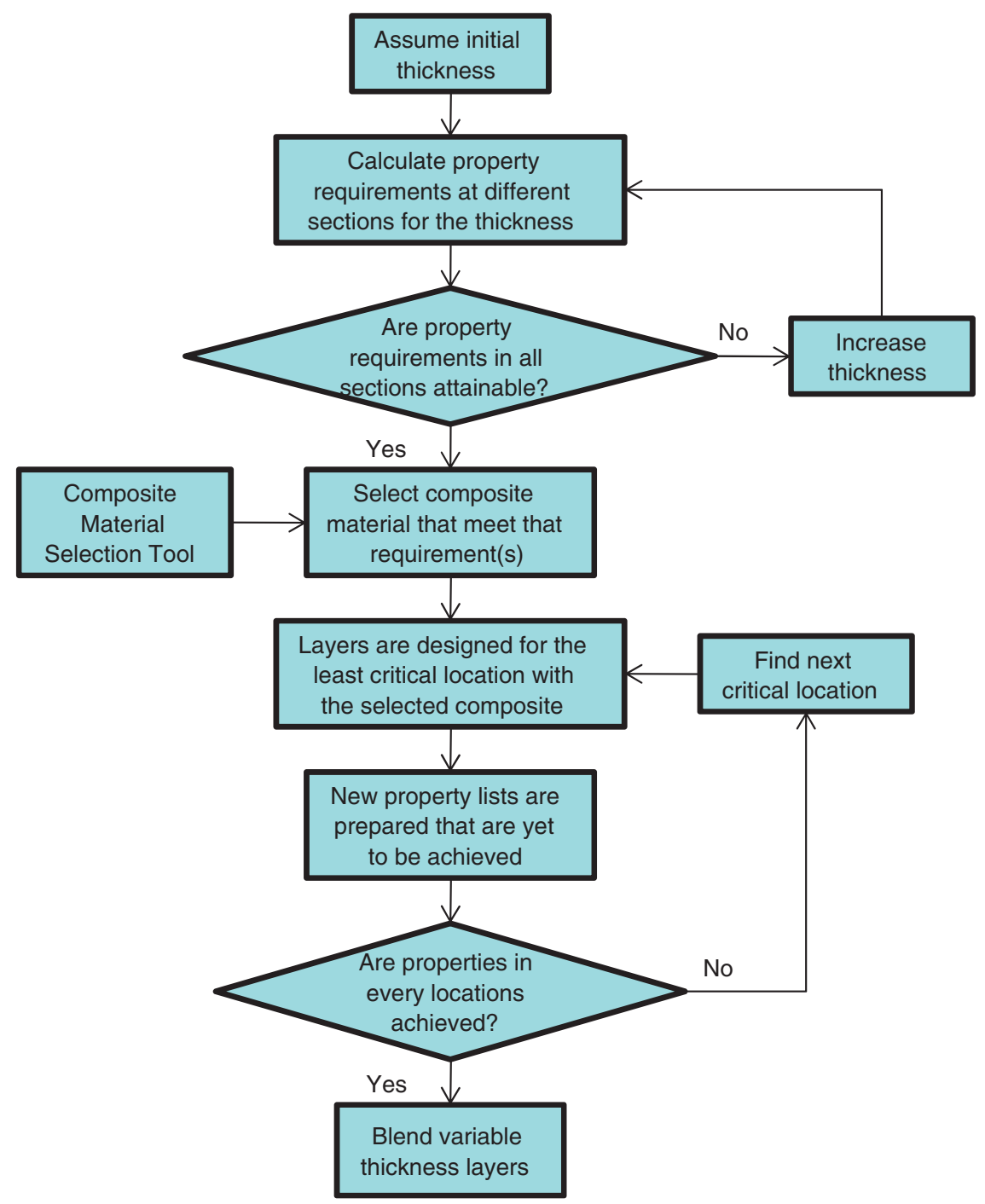

Figure 3. Sub-Approach 2 (manufacturing efficient method).

would provide most efficient design in most cases, as the goal of this approach is to avoid over-designing in any direction. Starting from a single ply, minimum thickness of laminate is determined for which at least one property-goal reaches an attainable value. Composite material is selected for the attainable goal(s) and initial layers are designed using the minimum thickness. The thickness is then increased and minimum thickness is determined to meet the next goal(s). Composite material is selected for current goal and corresponding layers are designed with the selected materials. The same procedure is repeated until all properties (goals) in different locations are achieved. Thus design goals are met for all locations of the component, before the thickness variations are blended to reduce stress concentration.

\subsection{Sub-Approach 2: Manufacturing Efficient}

The second sub-approach provides a way to design a component that will be efficient to manufacture.
This manufacturing efficient approach is based on the assumption that manufacturing is simple when same fiber-matrix composite is used for the entire product. The calculation begins with increasing the thickness until the property requirements in every section becomes attainable. Composite material is selected for the largest values among these property requirements. The design of layers takes place with the selected composite, based on the design loading conditions at different sections of the component. The steps in this sub-approach are shown in Figure 3.

\subsection{Sub-Approach 3: Cost Efficient}

The third approach is based on allowing maximum possible thickness for different locations in a component, while designing composite materials and their orientations. This is expected to be the least expensive approach by designing for maximum possible thickness in every location (design flexibility is maximum). 


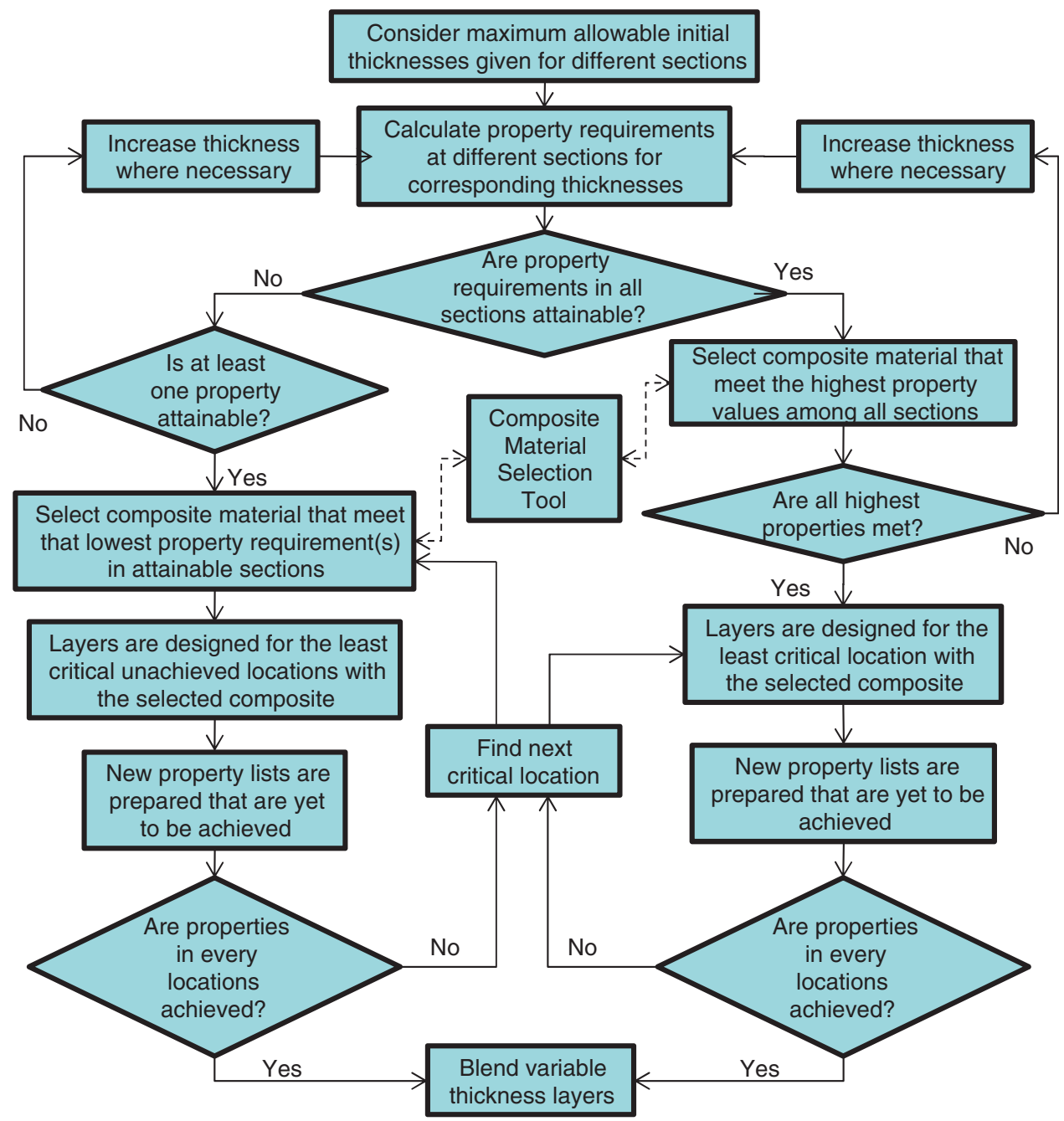

Figure 4. Sub-Approach 3 (cost efficient method).

This allows selection of the least expensive material(s) that may provide least allowable quality of materials, but will meet all desired property requirements. The design of layers may take place similar to any of the first two sub-approaches or a combination of both. The detailed steps in this sub-approach are shown in Figure 4.

Now that different locations of the body are designed with different numbers of composite layers (different thicknesses) a proper blending method is used in the last step of the approach to achieve a continuous inner (or, external) surface.

While designing an irregular shape component, the four phases in this approach may get intertwined with each other; however, the overall approach will still remain unchanged.

\section{The Composite Material Selection Tool}

The composite material selection tool has been developed with a focus to create a user-friendly environment for the selection of composite materials to meet multiple property goals. It can be used to select a percentage combination of filler material in a matrix with a specific fiber orientation to achieve multiple desired thermal and mechanical directional properties for a component.

The tool is composed of two databases. The first database contains information regarding different types of fibers, metals, and ceramics. The second database contains property information of different types of composite matrix. These various fibers, metals, or ceramics, and the matrix materials are distinguished for their compatibility in all possible combinations. Both these databases and the compatibility tool contain up-to-date information about various composite synthesizing methods and are always updatable for new innovations (Figure 5).

Different pre-selected micro-mechanical models for different properties and the lamination theory are incorporated with the databases to create a multidimensional properties database. The selection engine makes eight different stages of analysis and an optimized selection is made. 
A Root-Mean-Square (RMS) index concept is introduced in this tool, which is considered as the index for the selection. All possible combinations of fiber and matrix materials are analyzed for different orientations

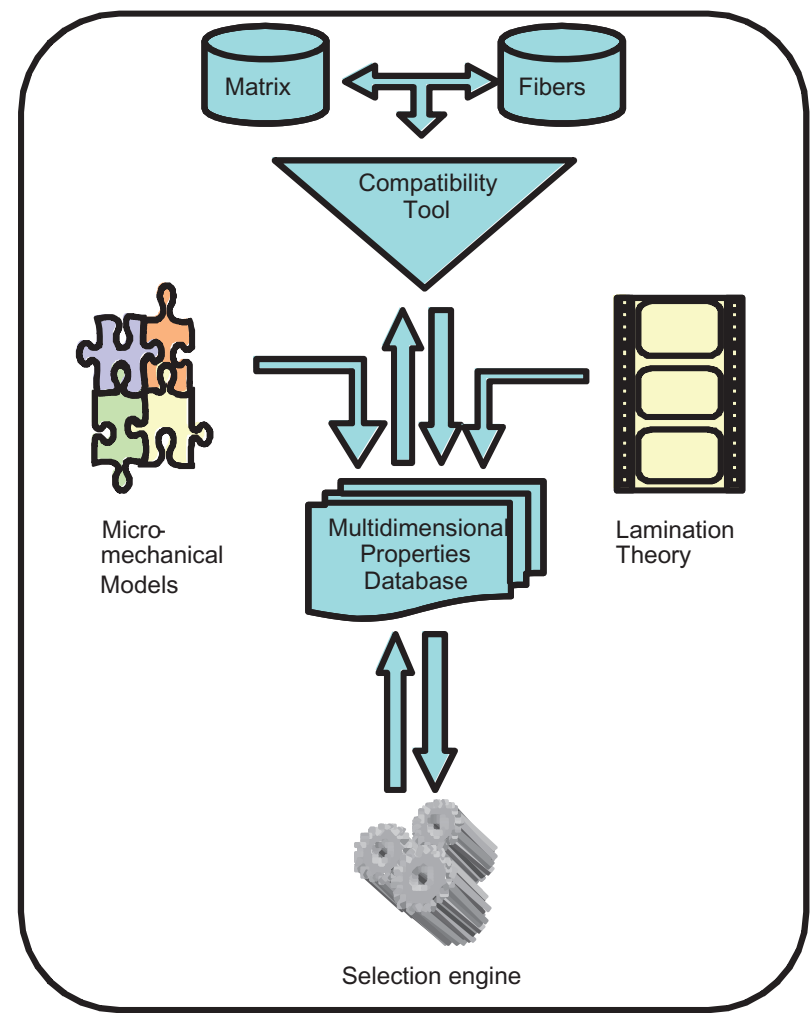

Figure 5. Composite material selection tool. and using the application of lamination theory, the directional properties are considered during analysis. Thus the multidimensional chart is obtained; each dimension stands for different property requirements. An RMS value is obtained for each composite combination according to the merits of closeness to the multiple property goals, which enables the tool to make the best selection. Finally the selected composite laminates are sorted according to their RMS index, and the expected properties are calculated using similar models. The tabulated result is shown as output to the designer. The basic properties of the materials from which selections are made are tabulated in Table 1. Combining these fibers with different matrix materials, it is possible to achieve a very wide range of properties (Figure 6).

\section{Case Study: Designing a Hip Replacement Using Composite}

To demonstrate the proposed approach a hip joint is designed using the shape grammar approach. The loading condition is illustrated by Hamrock et al. [33]. Figure 7 shows a total hip replacement inserted into a human femur and hip. Such devices are commonly used to treat painful arthritic conditions that result in loss of mobility. The operation consists of sawing off portions of the femur, reaming the femoral cavity to allow for implant insertion, and hammering the implant into the

Table 1. Properties of engineering materials, fibers, and matrix [34, p-7].

\begin{tabular}{|c|c|c|c|c|c|c|c|}
\hline \multirow{2}{*}{$\begin{array}{l}\text { Property } \\
\text { Units }\end{array}$} & \multicolumn{2}{|c|}{ Density, $\rho$} & \multicolumn{2}{|c|}{ Modulus, E } & \multirow[b]{2}{*}{ Poisson's ratio, $v$} & \multicolumn{2}{|c|}{ Strength, $\sigma_{\mathbf{u}}$} \\
\hline & $\mathrm{g} / \mathrm{cm}^{3}$ & lb/in ${ }^{2}$ & GPA & Msi & & MPA & ksi \\
\hline \multicolumn{8}{|l|}{ Material } \\
\hline \multicolumn{8}{|l|}{ Metals } \\
\hline Steel & 7.8 & 0.284 & 200 & 29 & 0.32 & 1724 & 250 \\
\hline Aluminum & 2.7 & 0.097 & 69 & 10 & 0.33 & 483 & 70 \\
\hline Titanium & 4.5 & 0.163 & 91 & 13.2 & 0.36 & 758 & 110 \\
\hline \multicolumn{8}{|l|}{ Fibers } \\
\hline AS4 & 1.8 & 0.065 & 235 & 34 & 0.2 & 3599 & 522 \\
\hline T300 & 1.76 & 0.064 & 231 & 33 & 0.2 & 3654 & 530 \\
\hline P100S & 2.15 & 0.078 & 724 & 105 & 0.2 & 2199 & 319 \\
\hline IM8 & 1.8 & 0.065 & 310 & 45 & 0.2 & 5171 & 750 \\
\hline Boron & 2.6 & 0.094 & 385 & 55.8 & 0.21 & 3799 & 551 \\
\hline Kevlar 49 & 1.44 & 0.052 & 124 & 18 & 0.34 & 3620 & 525 \\
\hline SCS-6 & 3.3 & 0.119 & 400 & 58 & 0.25 & 3496 & 507 \\
\hline Nicalon & 2.55 & 0.092 & 180 & 28 & 0.25 & 2000 & 290 \\
\hline Alumina & 3.95 & 0.143 & 379 & 55 & 0.25 & 1585 & 230 \\
\hline S-2 Glass & 2.46 & 0.09 & 86.8 & 12.6 & 0.23 & 4585 & 665 \\
\hline E-Glass & 2.58 & 0.093 & 69 & 10 & 0.22 & 3450 & 550 \\
\hline Sapphire & 3.97 & 0.143 & 435 & 63 & 0.28 & 3600 & 522 \\
\hline \multicolumn{8}{|l|}{ Matrix materials } \\
\hline Epoxy & 1.38 & 0.05 & 4.6 & 0.67 & 0.36 & 58.6 & 8.5 \\
\hline Polyimide & 1.46 & 0.053 & 3.5 & 0.5 & 0.35 & 103 & 15 \\
\hline Copper & 8.9 & 0.32 & 117 & 17 & 0.33 & 400 & 58 \\
\hline Silicon carbide & 3.2 & 0.116 & 400 & 58 & 0.25 & 310 & 45 \\
\hline
\end{tabular}




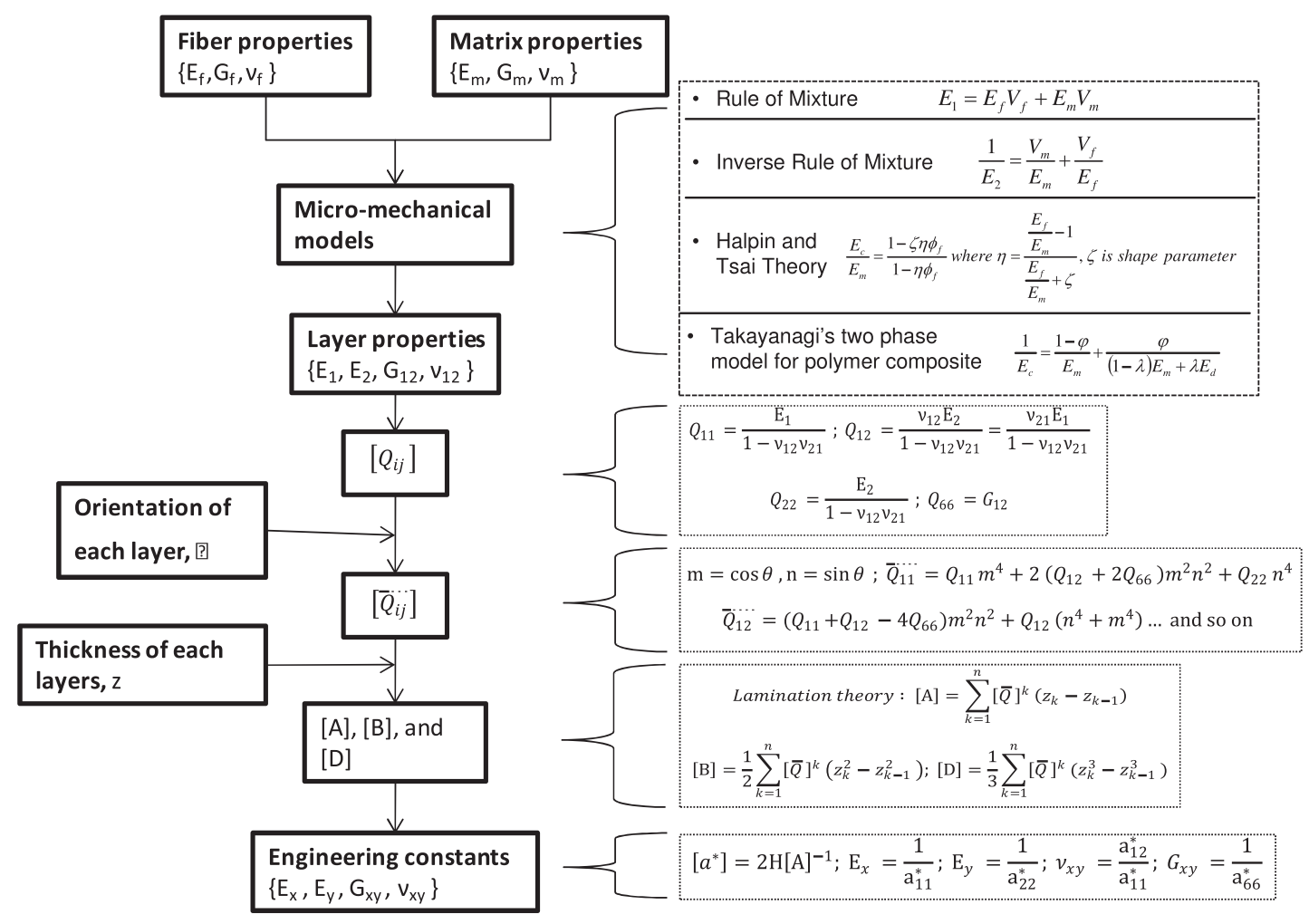

Figure 6. Composite material selection flow chart.

femur. The hip portion of the implant is similarly installed, often with screws. The femur portion of the implant includes a stem onto which the highly polished ball is attached. Mass customization of total hip replacement joint will satisfy size constraints more accurately for individual patients.

In this article the hip replacement joints are customized based on the size and shape of the hip and femur of the patient. The set of shape and size constraints considered for the design are as follows:

- Shape constraint: The stem of the component (top portion) have to be round, this part is designed to fit inside a highly polished ball. The root will have a $3^{\circ}$ taper at the bottom. There is an angle between the root and the stem of about $36.5^{\circ}$.

- Size constraint: The inside diameter of the polished ball, where the stem will be inserted, is 0.50 in. $(12.7 \mathrm{~mm})$, this defines the outside diameter of the stem. For the proper observation and maintenance of the component, it is required to place some sensors inside the component. So, a hollow body is expected. The thickness of the surface is assumed to be maximum $4 \mathrm{~mm}$.

- Bone strain: It has been found that due to tensile loading in the longitudinal direction, human bone yields at a strain of $6.7 \times 10^{-3}$ and fractures at a strain of 0.03 [35]. In this case study, the design strain is considered as $6.7 \times 10^{-3}$.
Other general details of the size and shape constraints are provided in Figure 7.

\subsection{Assumptions}

The commonly used implant materials are cast cobalt chromium, forged stainless steel, and Ti-6Al-4V (titanium alloy). For this case study, we intend to design the implant using composite material. While designing for commercial use, the selection of material must consider compatibility with human body as this implant will be in direct contact to the inner parts of the human body. However, the case study presented in this article is prepared with a purpose to explain the design approach only, and for this design, the material compatibility is not considered. We assume all the composite materials considered are compatible with human body.

\subsection{Functional Design}

The basic functional requirements for the hip joint are translated into initial design shape in two steps:

\subsubsection{INITIAL SHAPE}

The basic function of the component is to provide a two-way joint between hip and the femur. So, a number of parametric points can be considered as the initial shape. A minimum of three points are required to 
(a)

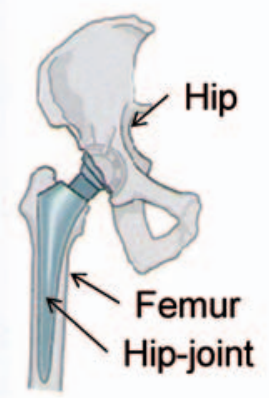

(c)

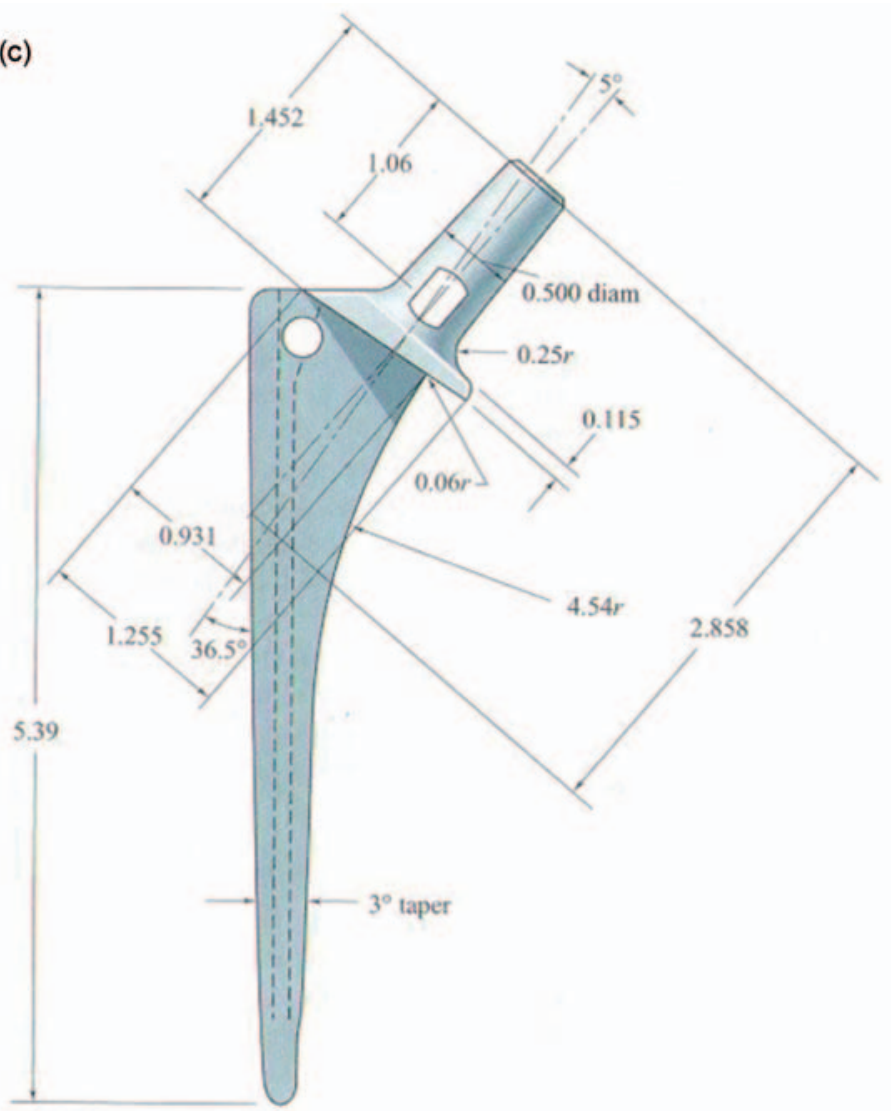

Figure 7. Total hip replacement joint and design dimensions: (a) a total hip replacement joint inserted into a human femur and hip, (b) commercially available hip replacement joint of similar look, (c) dimension of femoral implant in inches [33].

express this rule. However, we consider five points for more accuracy as given in Figure 8(a).

\subsubsection{RULE 1: DEFINING ANGLE}

In case of biomechanics of walking, the actual load applied to a hip joint is complex and varies from person to person. Although the direction of applied force can vary by as much as $30^{\circ}$, it is assumed that the load direction is vertical and centered on the stem. This is also a worst-case assumption, as any inclination of the load reduces the bending moment at any location. Considering all these situations, the angle between two main parts (stem and root, as given in Figure 8) of the joint can be defined using the first rule, as shown in Figure 8(b).

\subsection{Form Design}

In this phase, three shape formation rules are defined to capture the general shape of the hip joint.

\subsubsection{RULE 2: DEFINING CROSS-SECTION}

The geometrical entity 'point' will be replaced by another geometrical entity to define cross-section at different locations of the body. The possible entities are square, rectangle, circle, oval, etc. For this case study, cross-section for location $\mathrm{a}, \mathrm{b}$, and e are selected to be circles, as they are required to set inside round holes either inside the smooth ball or the round bone, while cross-section at location $\mathrm{c}$ and $\mathrm{d}$ could be a circle, rectangle, oval, etc. To capture the general shape of the component, we consider rectangular section for this case study (Figure 8(c)). In some instances the cross-sections could be irregular in shape; however, for this case study we will consider regular circle and rectangle only.

\subsubsection{RULE 3: SWEEP SHAPE}

The outer shape requirements for hip replacement case study may be unique for each individual case, as this is going to replace a part of human body, the size of which may vary from person to person. Using the basic sweeping rules as explained by Agarwal and Cagan [1], a 3D surface can be generated through the cross-sections to generate the initial outer shell of the component (Figure 8(d)).

\subsubsection{RULE 4: MEETING THE OUTER SHAPE REQUIREMENTS}

The dimensional requirements are provided by the user as mentioned before. In this case study we intend to capture the general shape of a hip replacement joint. Thus, in addition to those requirements, we consider an 

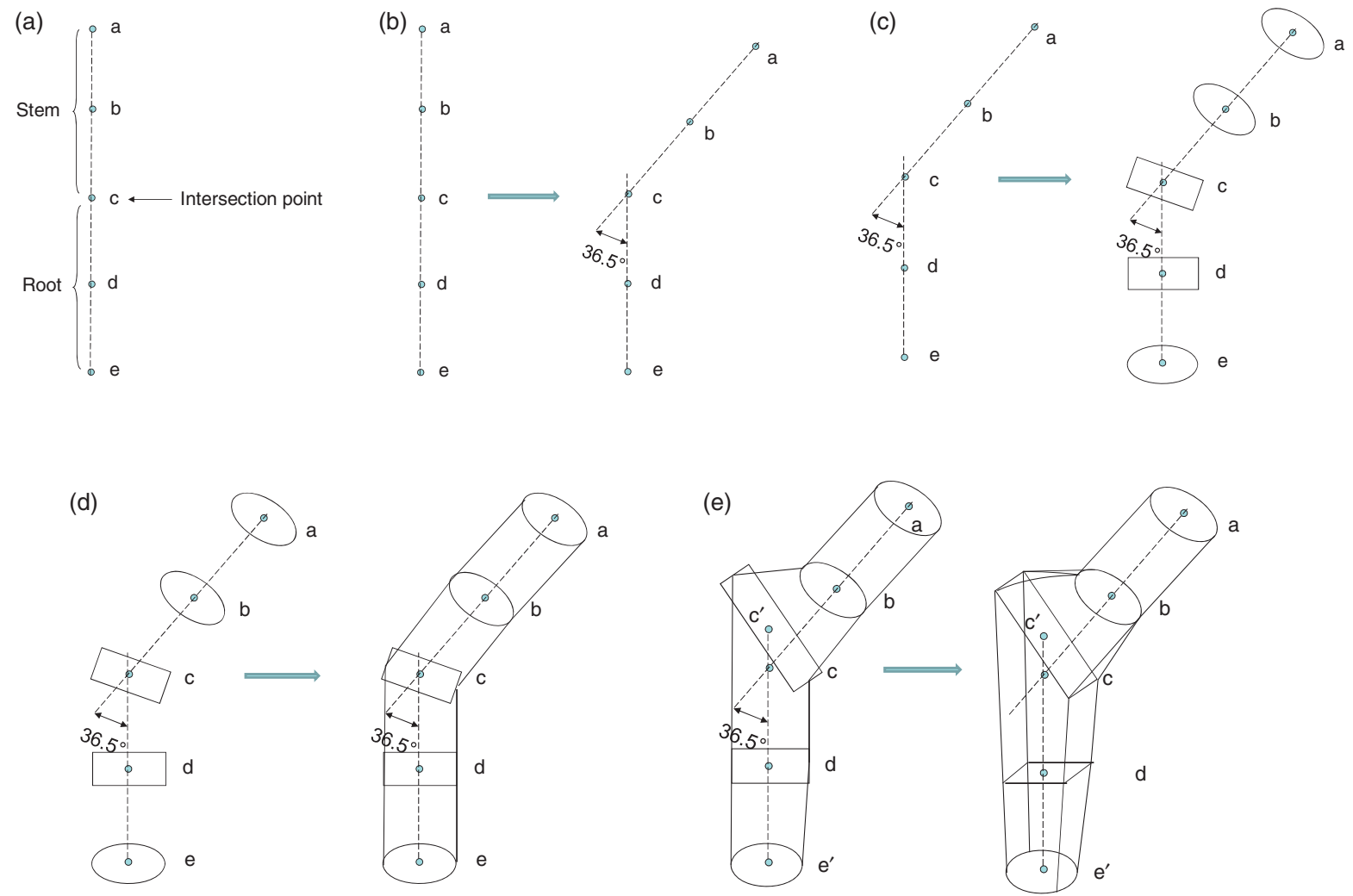

Figure 8. Generating outer shell of the hip replacement joint using shape rules: (a) defining initial shape, (b) Rule 1 - defining angle, (c) Rule 2 defining cross-section, (d) Rule 3 - sweep shape, (e) Rule 4 - outer shell.

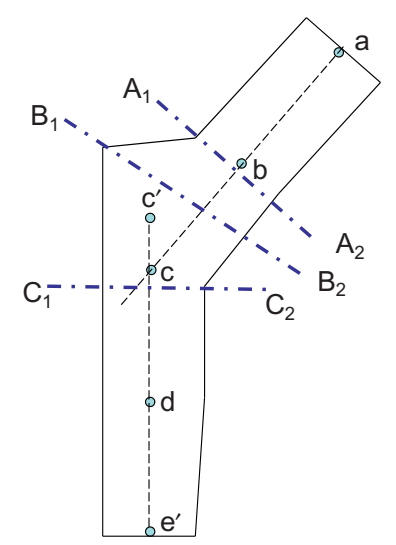

Figure 9. Critical sections of the hip replacement joint.

elbow shape extrusion extended from the intersection point c, and $3^{\circ}$ taper shape at point e (Figure 8(e)).

As can be seen from Figure 8(e), the rectangle at point $\mathrm{c}$ is extended to create an elbow. The center of the rectangle is moved upward to a new point $\mathrm{c}^{\prime}$, but still the angle between the stem and the root remains same, which is measured at point $\mathrm{c}^{\prime}$. At the same time circle at point e constricted a bit toward left to create a taper of $3^{\circ}$ at the edge. Thus point e will be replaced by point $\mathrm{e}^{\prime}$. Adding the dimensions as mentioned above, the final form of outer shell of Figure 8(e) can be found similar to commercially used hip replacement is as shown in Figure 7(b).

\subsection{Material and Loading Design}

Four coupled rules, that use loading analysis with composite material selection tool, are used to select the material.

\subsubsection{RULE 5: DEFINING 'CRITICAL' SECTIONS'}

As explained by Hamrock et al. [33, p. 255] using general knowledge of Solid Mechanics, it can be determined that the critical sections for this case study are $A_{1}-A_{2}, B_{1}-B_{2}$, and $C_{1}-C_{2}$ as shown in the Figure 9 . These sections are selected because they have geometric features that act as stress raisers and because their locations maximize the stresses associated with the applied loads.

\subsubsection{RULE 6: CREATING CHART TO DETERMINE PROPERTY REQUIREMENTS}

The challenge of the problem lies in obtaining the stresses. The actual load applied to a hip joint is extremely complicated and varies from person to person. Given that the loading can be complex, the load was taken four times the user's body weight, a peak force measured during a walking step. It is assumed that the 
Table 2. Applied loads [33].

\begin{tabular}{|c|c|c|c|c|c|c|}
\hline \multirow{2}{*}{ Section } & \multicolumn{2}{|c|}{ Normal force } & \multicolumn{2}{|c|}{ Shear force } & \multicolumn{2}{|c|}{ Moment } \\
\hline & lb & $\mathbf{N}$ & lb & $\mathbf{N}$ & in.lb & N.m \\
\hline$A_{1}-A_{2}$ & 640 & 2846.862 & 475 & 2112.905 & 252 & 28.47218 \\
\hline$B_{1}-B_{2}$ & 640 & 2846.862 & 475 & 2112.905 & 345 & 38.97977 \\
\hline $\mathrm{C}_{1}-\mathrm{C}_{2}$ & 800 & 3558.577 & 0 & 0 & 680 & 76.82968 \\
\hline
\end{tabular}

most implant recipients are elderly or have a less active lifestyle, thus running is not considered for the design. Thus considering a $200 \mathrm{lb}$ user, the design weight on the implant is found to be $800 \mathrm{lb}$.

The following chart (Table 2) is determined directly by using methods of statics that shows how the design weight leads to a normal force, a shear force, and a bending moment at each section.

As this component is to be made using composite materials, there will be three main design requirements: the longitudinal modulus, the transverse modulus, and the shear modulus. Since, the presence of weight of the person is the only load applied vertically to the component and does not involve torsion, no transverse modulus requirements need to be satisfied during design. The unidirectional composite layers can be used to achieve all the design goals by placing them in vertical planes, without any angular orientation. Table 3 is prepared to calculate required modulus, while varying thicknesses for different loading sections. As the same maximum allowable (design) strain is considered throughout the component body, an incremental increase in thickness will improve the stiffness of the part, thus reduce the resulting maximum strain under the design loading. Once the maximum strain under the design load is below the allowed limit, longitudinal and shear modulus for different sections will be accepted as designed. The equations used for such calculations are provided in each cells of the chart.

\subsubsection{RULES 7 AND 8: SELECTING APPROPRIATE MATERIAL(S) AND DESIGNING THICKNESSES FOR DIFFERENT LOCATIONS}

These two rules, act as a single rule and follow three sub-approaches mentioned in Section 2. The subapproaches for this case are as follows:

\subsubsection{Sub-Approach 1 (Weight Efficient Method):}

The first sub-approach is expected to ensure maximum weight reduction by avoiding over designing in any direction. As mentioned before, the calculation begins with determining a minimum initial thickness for which at least one property goal reaches a value that can be achieved by available composite material options.

In this case study, while designing the initial layers, a thickness of $0.095 \mathrm{~mm}$ is found that brings required longitudinal modulus at point $\mathrm{B}_{2}$ (at Section $\mathrm{B}_{1}-\mathrm{B}_{2}$ ) an achievable value of $70 \mathrm{GPa}$. Table 4 shows this condition (highlighted cell shows the design requirement).

Using the composite material selection tool, the selected composite material for this goal is AS4 as fiber and Epoxy as matrix material, the theoretical fibervolume fraction to achieve the property is $35 \%$. Thus the initial laminate is designed to be composed of only one layer using the selected composite. Considering a typical thickness for AS4-Epoxy unidirectional laminate to be $0.1 \mathrm{~mm}$, the thickness for the designed laminate is also found $0.1 \mathrm{~mm}$. Since, the allowable strain is considered constant $\left(6.7 \times 10^{-3}\right)$, this updated thickness reduces the design requirement for longitudinal modulus at location $\mathrm{B}_{2}$ to 62 as shown in Table 4. Achieved modulus for this initial layer is $86 \mathrm{GPa}$, which is above the requirement for this thickness. The selected composite for this run meets the requirement for $\mathrm{B}_{2}$ location only.

Increasing previous thickness of $0.1 \mathrm{~mm}$ the next attainable goal(s) are determined using the chart shown in Table 3. Longitudinal modulus of $99 \mathrm{GPa}$ at point $\mathrm{A}_{1}$ is the next achievable location. Thus, the increase in thickness brings us to an additional thickness of $0.12 \mathrm{~mm}$ (a total of $0.22 \mathrm{~mm}$ ) for which the design properties are shown in Table 5. It should be noted that the achieved property cell is removed from this table and is not considered for future calculations.

The next laminate, that will be adjacent to the previous selected laminate from inside, is designed by selecting Boron-Epoxy composite with $40 \%$ volume fraction (1 layer, i.e., $0.0 .14 \mathrm{~mm}$ ), that posses longitudinal modulus of $128 \mathrm{GPa}$ and shear modulus of 3.67 GPa. In addition to meeting the design requirement for Location $A_{1}$, this selection achieves longitudinal modulus requirements for Location $\mathrm{B}_{1}$ as well (Table 5). In the same manner, next laminates and their materials are designed; the details of these layers for this case study are shown in Table 6 .

As shown in Table 6, both the longitudinal and shear modulus requirements are achieved after the fourth laminate. Thus the thinnest Sections $\left(\mathrm{A}_{1}-\mathrm{A}_{2}\right.$ and $\left.\mathrm{C}_{1}-\mathrm{C}_{2}\right)$ of the component will consist of first four laminates. Section $\mathrm{B}_{1}-\mathrm{B}_{2}$, will be comprised of all five laminates according to this method.

\subsubsection{Sub-Approach 2 (Production Efficient Method):}

As mentioned before, this method is based on the assumption that composite material manufacturing is 


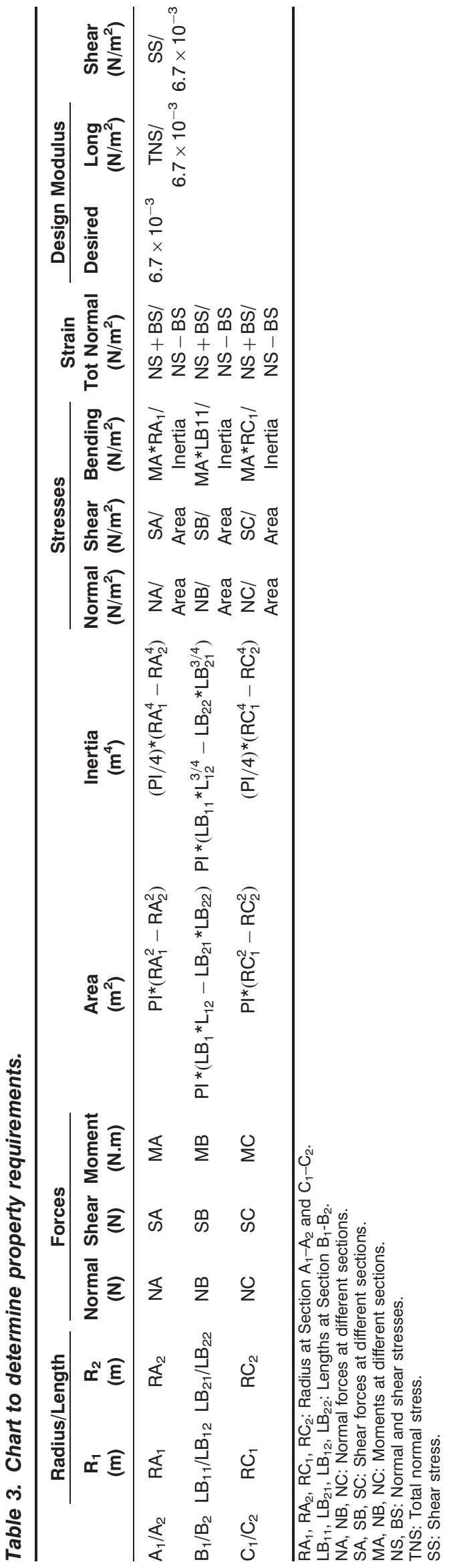

most efficient when the designed fiber-matrix combination remains same for the whole product. Equations given in Table 3 are used to determine the minimum thickness for which properties in each and every location in the body becomes obtainable.

For this case study, total thicknesses of $2.2 \mathrm{~mm}$ bring attainable values of longitudinal and shear modulus requirements for every location. Using the 'Composite Material Customization Tool', Sapphire fiber is selected with Epoxy matrix material to meet design goal of longitudinal modulus of $287 \mathrm{GPa}$ and shear modulus of 5.7 GPa (Table 7), which are the most critical loads for any location. A typical thickness of $0.11 \mathrm{~mm}$ for each Sapphire-Epoxy layers will accommodate 20 layers with $65 \%$ volume fraction to meet these requirements. This composite material, selected for the most critical section, is used to design thicknesses for other locations starting from the least critical section using steps similar to Weight Efficient Method (Sub-Approach 1). Table 7 shows the selected materials and the thicknesses of the design performed using this method.

\subsubsection{Sub-Approach 3 (Cost Efficient Method):}

The Cost Efficient Method is based on the assumption that greater range of design thickness provides greater freedom to the selection of material. Thus, if maximum thickness is allowed for each different location of a component, the cheapest materials can be selected to design it. To demonstrate the approach in this case study, a maximum thickness of $2.00 \mathrm{~mm}$ for Section $\mathrm{A}_{1}$ $\mathrm{A}_{2}, 1.00 \mathrm{~mm}$ for Section $\mathrm{B}_{1}-\mathrm{B}_{2}$, and $2.5 \mathrm{~mm}$ for Section $\mathrm{C}_{1}-\mathrm{C}_{2}$ is assumed. If the property requirements at all sections are attainable by the cheapest material, the design follows Production Efficient Method (SubApproach 2) with that material. Otherwise, all attainable sections are designed using the cheaper selection(s) and the remaining sections are designed with costlier composites to ensure that the design requirements are achieved. To demonstrate the approach with comparison of prices, we will design the component using three types of composites: (i) the comparatively cheaper option made of Glass fiber with a typical layer thickness of $0.18 \mathrm{~mm}$, (ii) AS4 Graphite fiber, which is costlier than Glass fiber, with typical layer thickness about $0.1 \mathrm{~mm}$, and (iii) The more expensive P 100S fiber with layer thickness of $0.3 \mathrm{~mm}$. Thus the goal is to use Glass fiber more and AS4 and P 100S fiber as less as possible in this design.

For maximum allowable thickness at each location, it was determined that shear modulus at Section $\mathrm{B}_{1}-\mathrm{B}_{2}$ and longitudinal modulus at Section $\mathrm{C}_{1}-\mathrm{C}_{2}$ cannot be achieved using only Glass-Epoxy composites. So, for these sections, design is carried out with a combination of Glass, AS4, and P100S, while ensuring that minimum possible AS4 is used, and maximum allowable thicknesses are not exceeded. The design requirements at 
Table 4. Design properties for thickness $0.095 \mathrm{~mm}$ and achieved properties for thickness $0.1 \mathrm{~mm}$.

\begin{tabular}{lccccc}
\hline \multirow{2}{*}{ Section } & \multicolumn{2}{c}{ Design properties } & & \multicolumn{2}{c}{ Achieved properties } \\
\cline { 2 - 3 } & Longitudinal modulus (GPa) & Shear modulus (GPa) & & Longitudinal modulus (GPa) & Shear modulus (GPa) \\
\hline$A_{1}$ & 248 & 84 & 236 & 79 \\
$A_{2}$ & 474 & 84 & 450 & 79 \\
$B_{1}$ & 213 & 104 & 206 & 99 \\
$B_{2}$ & 70 & 104 & 62 & 99 \\
$C_{1}$ & 2511 & $N / A$ & 2390 & N/A \\
$C_{2}$ & 2984 & $N / A$ & 2840 & N/A \\
\hline
\end{tabular}

Table 5. Design properties for thickness $0.22 \mathrm{~mm}$ and achieved properties for thickness $0.091 \mathrm{~mm}$.

\begin{tabular}{lccccc}
\hline & \multicolumn{2}{c}{ Design properties } & & Achieved & \multirow{2}{*}{ Properties } \\
\cline { 2 - 3 } Section & Longitudinal modulus (GPa) & Shear modulus (GPa) & & Longitudinal modulus (GPa) & Shear modulus (GPa) \\
\hline $\mathrm{A}_{1}$ & 99 & 32 & 32 & 102 & 33 \\
$\mathrm{~A}_{2}$ & 185 & 40 & 193 & 33 \\
$\mathrm{~B}_{1}$ & 121 & 40 & 124 & 42 \\
$\mathrm{~B}_{2}$ & Achieved & $\mathrm{N} / \mathrm{A}$ & Achieved & \\
$\mathrm{C}_{1}$ & 1018 & $\mathrm{~N} / \mathrm{A}$ & 1056 & $\mathrm{~N} / \mathrm{A}$ \\
$\mathrm{C}_{2}$ & 1202 & $\mathrm{~N} / \mathrm{A}$ & \\
\hline
\end{tabular}

Table 6. Results for sub-approach 1 (weight efficient method).

\begin{tabular}{|c|c|c|c|c|c|c|c|c|}
\hline Layer & Fiber & Number of plies & Thickness (mm) & Vf (\%) & Section & Design property & Required (GPa) & Achieved (GPa) \\
\hline 1 & AS4 & 1 & 0.1 & 35 & $\mathrm{~B}_{2}$ & Longitudinal modulus & 63 & 86 \\
\hline \multirow[t]{2}{*}{2} & Boron & 1 & 0.14 & 40 & $A_{1}$ & Longitudinal modulus & 102 & 128 \\
\hline & & & & & $\mathrm{B}_{1}$ & Longitudinal modulus & 124 & 128 \\
\hline 3 & Boron & 1 & 0.14 & 35 & $\mathrm{~A}_{2}$ & Longitudinal modulus & 126 & 132 \\
\hline \multirow[t]{4}{*}{4} & P 100S & 3 & 0.9 & 65 & $A_{1}$ & Shear modulus & 6.9 & 7.61 \\
\hline & & & & & $\mathrm{A}_{2}$ & Shear modulus & 6.9 & 7.61 \\
\hline & & & & & $\mathrm{C}_{1}$ & Longitudinal modulus & 307 & 374 \\
\hline & & & & & $\mathrm{C}_{2}$ & Longitudinal modulus & 349 & 374 \\
\hline \multirow[t]{2}{*}{5} & P 100S & 2 & 0.6 & 45 & $\mathrm{~B}_{1}$ & Shear modulus & 6.5 & 6.59 \\
\hline & & & & & $\mathrm{B}_{2}$ & Shear modulus & 6.5 & 6.59 \\
\hline
\end{tabular}

Table 7. Results for sub-approach 2 (production efficient method).

\begin{tabular}{|c|c|c|c|c|c|c|c|c|}
\hline Layer & Fiber & Number of plies & Thickness (mm) & Vf (\%) & Section & Design property & Required (GPa) & Achieved (GPa) \\
\hline 1 & Sapphire & 1 & 0.11 & 65 & $\mathrm{~B}_{2}$ & Longitudinal modulus & 51 & 289 \\
\hline \multirow[t]{2}{*}{2} & Sapphire & 1 & 0.11 & 65 & $A_{1}$ & Longitudinal modulus & 111 & 289 \\
\hline & & & & & $\mathrm{B}_{1}$ & Longitudinal modulus & 130 & 289 \\
\hline 3 & Sapphire & 1 & & 65 & $\mathrm{~A}_{2}$ & Longitudinal modulus & 143 & 289 \\
\hline \multirow[t]{2}{*}{4} & Sapphire & 8 & 0.88 & 65 & $A_{1}$ & Shear modulus & 7.2 & 9.08 \\
\hline & & & & & $\mathrm{A}_{2}$ & Shear modulus & 7.2 & 9.08 \\
\hline \multirow[t]{2}{*}{5} & Sapphire & 3 & 0.33 & 65 & $\mathrm{~B}_{1}$ & Shear modulus & 7.5 & 9.08 \\
\hline & & & & & $\mathrm{B}_{2}$ & Shear modulus & 7.5 & 9.08 \\
\hline 6 & Sapphire & 1 & 0.11 & 65 & $\mathrm{C}_{1}$ & Longitudinal modulus & 263 & 289 \\
\hline 7 & Sapphire & 1 & 0.11 & 65 & $\mathrm{C}_{2}$ & Longitudinal modulus & 287 & 289 \\
\hline
\end{tabular}


Table 8. Results for sub-approach 3 (cost efficient method).

\begin{tabular}{|c|c|c|c|c|c|c|c|c|}
\hline Layer & Fiber & Number of plies & Thickness (mm) & $V_{f}(\%)$ & Section & Design property & Required (GPa) & Achieved (GPa) \\
\hline 1 & Glass & 1 & 0.18 & 65 & $\mathrm{~B}_{2}$ & Longitudinal modulus & 6.1 & 59.74 \\
\hline 2 & Glass & 2 & 0.36 & 65 & $A_{1}$ & Longitudinal modulus & 50 & 59.74 \\
\hline 3 & Glass & 2 & 0.36 & 65 & $\mathrm{~A}_{2}$ & Longitudinal modulus & 58.9 & 59.74 \\
\hline \multirow[t]{3}{*}{4} & AS4 & 2 & 0.2 & 65 & $\mathrm{~B}_{1}$ & Longitudinal modulus & 67 & 77.27 \\
\hline & & & & & $A_{1}$ & Shear modulus & 7.8 & 7.59 \\
\hline & & & & & $\mathrm{A}_{2}$ & Shear modulus & 7.8 & 7.59 \\
\hline \multirow[t]{2}{*}{5} & Glass & 3 & 0.54 & 65 & $\mathrm{~B}_{1}$ & Shear modulus & 7.2 & 7.51 \\
\hline & & & & & $\mathrm{B}_{2}$ & Shear modulus & 7.2 & 7.51 \\
\hline 6 & P 100S & 5 & 1.5 & 65 & $\mathrm{C}_{1}$ & Longitudinal modulus & 252 & 263 \\
\hline 7 & P 100S & 1 & 0.3 & 65 & $\mathrm{C}_{2}$ & Longitudinal modulus & 276 & 282 \\
\hline
\end{tabular}

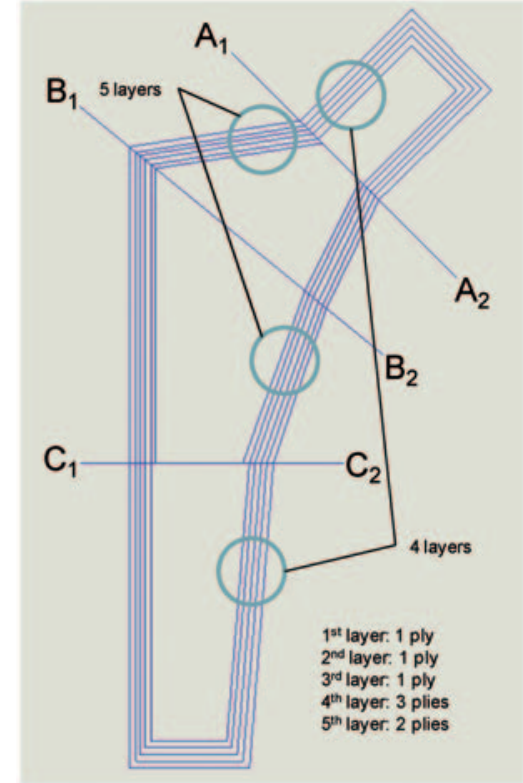

(a)

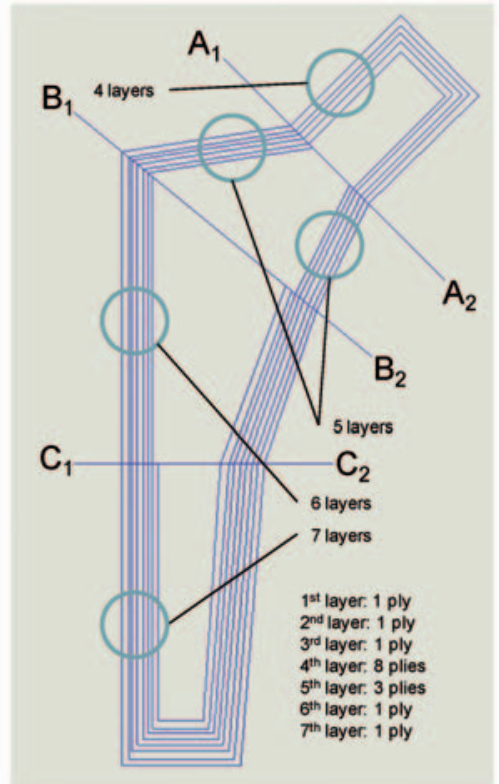

(b)

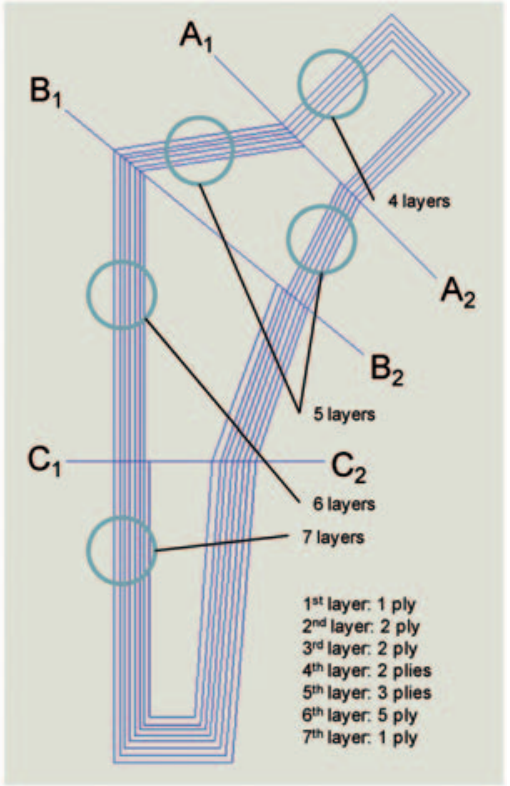

(b)

Figure 10. Layer design for different methods: (a) weight efficient method, (b) manufacturing efficient method, (c) cost efficient method.

remaining sections are achieved adding Glass-Epoxy layers only so that cheapest design is obtained. The result of the selection is given in Table 8 .

\subsection{Laminate Design}

The following rule is used to design blended laminate, while varying thicknesses, to reduce stress concentration.

Rule 10: Blending inner shell for different thicknesses

Designing composite panels with specified local loads could result in manufacturing incompatibilities between adjacent panel designs. A guide based optimization was employed by Adams et al. [25,36] to select composite panels to overcome this incompatibilities and the inner or outer surface was blended for utilizing a simple master-slave parallel implementation. This master-slave blending method is implemented in the final part of this approach to ensure a design that would be feasible to manufacture.

Designing and selection of composite materials for different layers, as explained in Section 4.4, are done such a way that the same layer contains same fiberreinforced composite of same orientation. Thus blending of inner surface for this case is primarily concerned with this continuation of same fiber-reinforced layers and of the same orientation. The initially selected layers and composite creates the outer shell and is constant throughout the body. The next layers are attached to the outer shell from the inner side and are distributed everywhere inside the outer shell; they are discontinued only where the design goals are met by previous layers. The cross-section of the hip joint after the laminates design should look like Figure 10(a)-(c). 


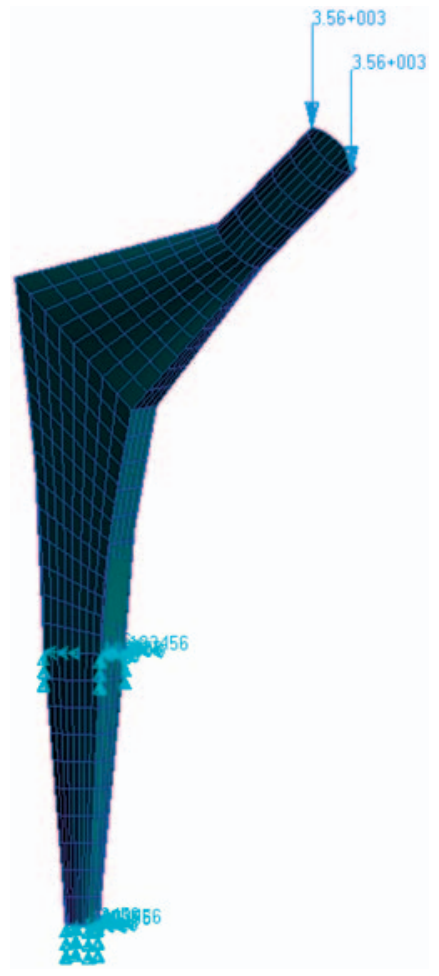

Figure 11. Loaded component with mesh elements, prepared for finite element analysis.

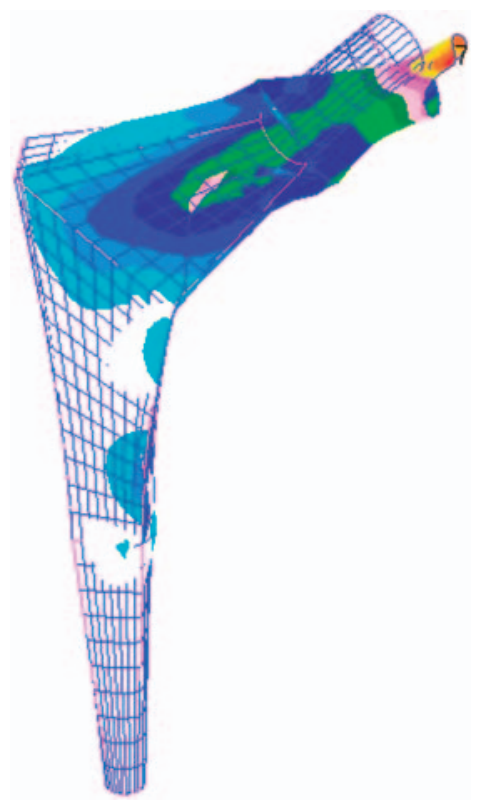

Figure 13. Deformed shape at failure.

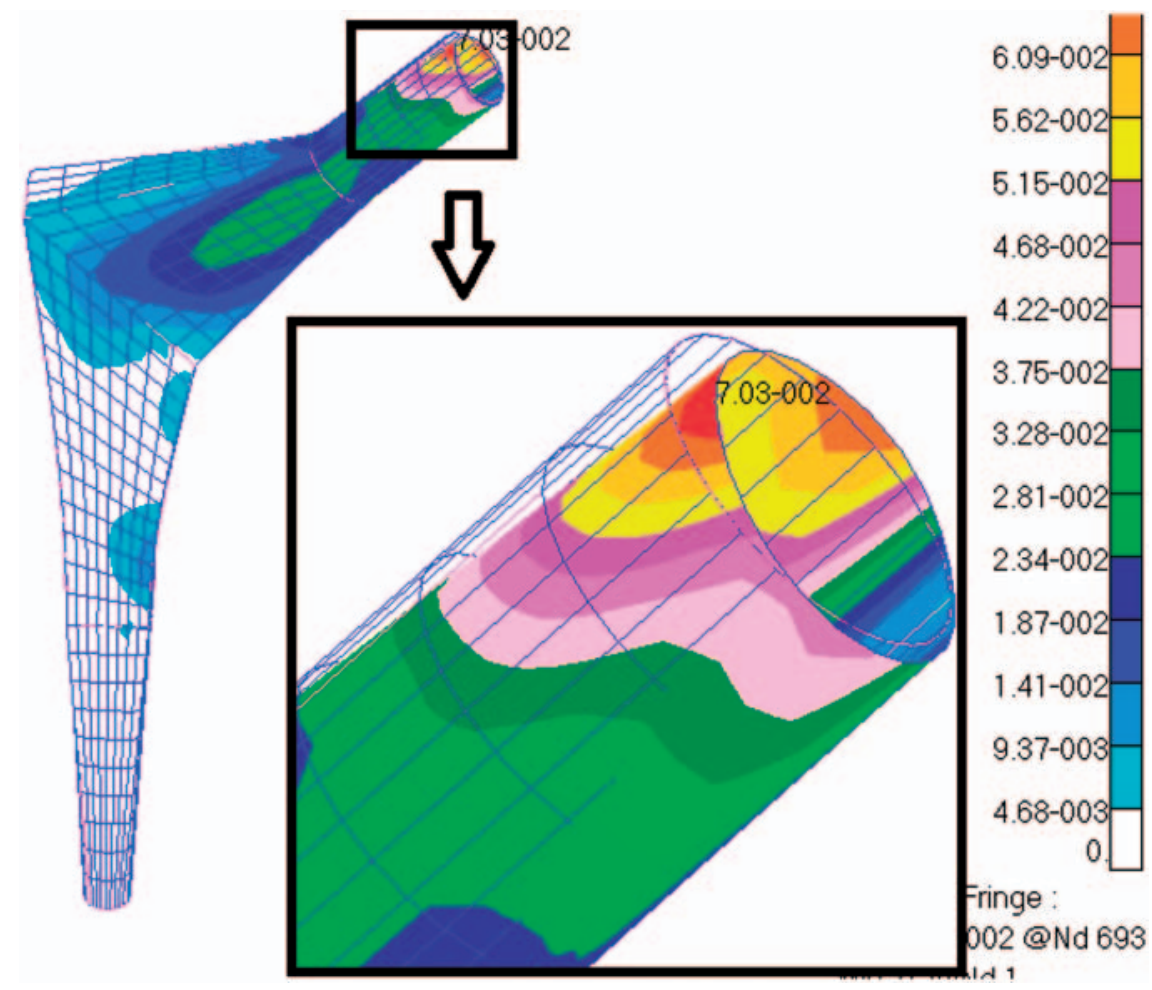

Figure 12. Deformation under vertical load. 
(a)

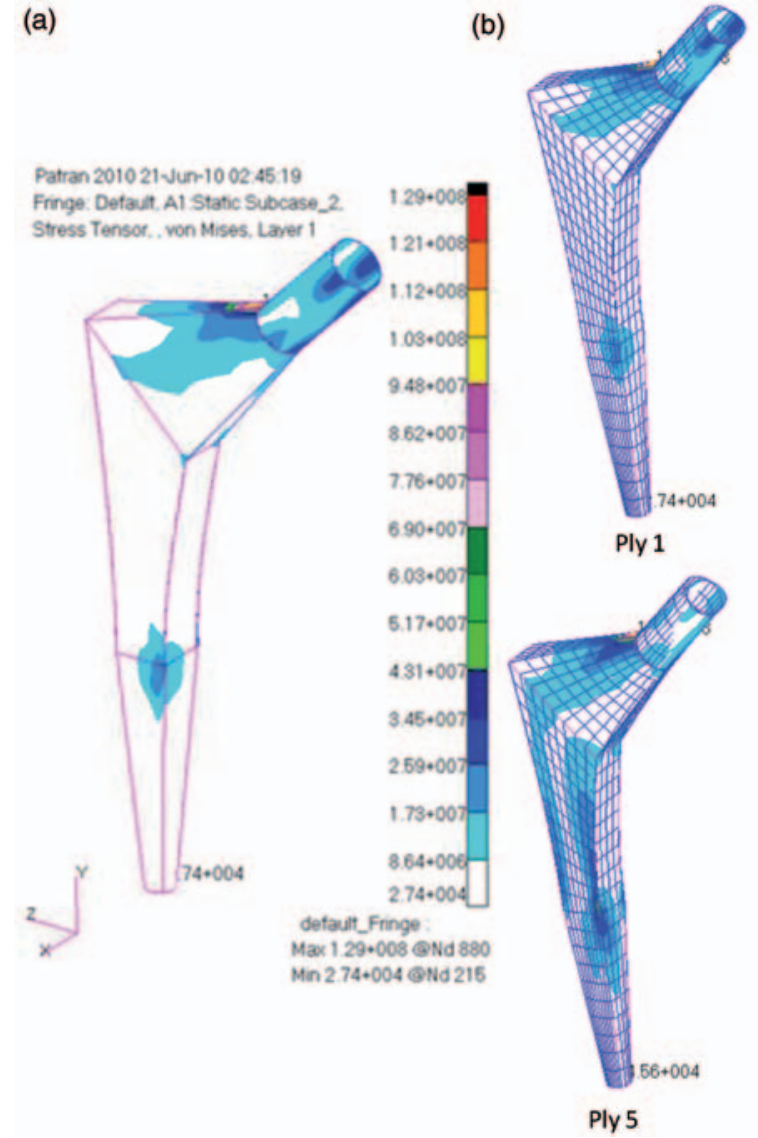

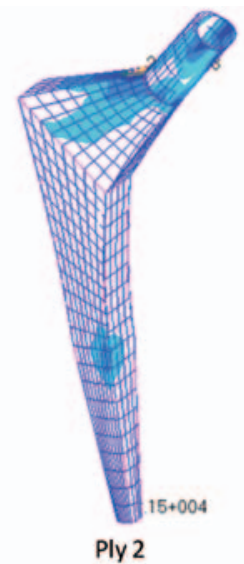

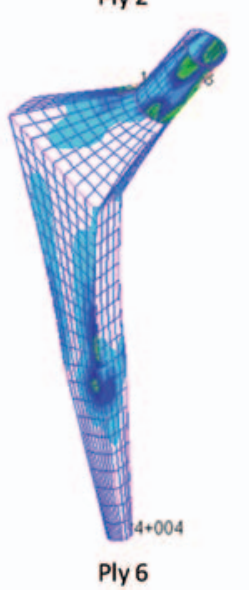

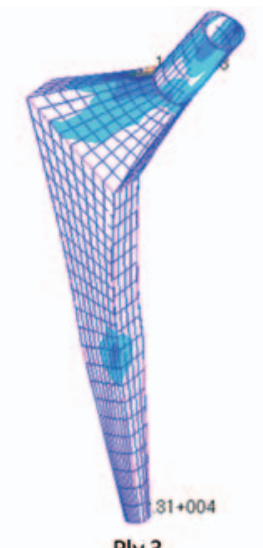
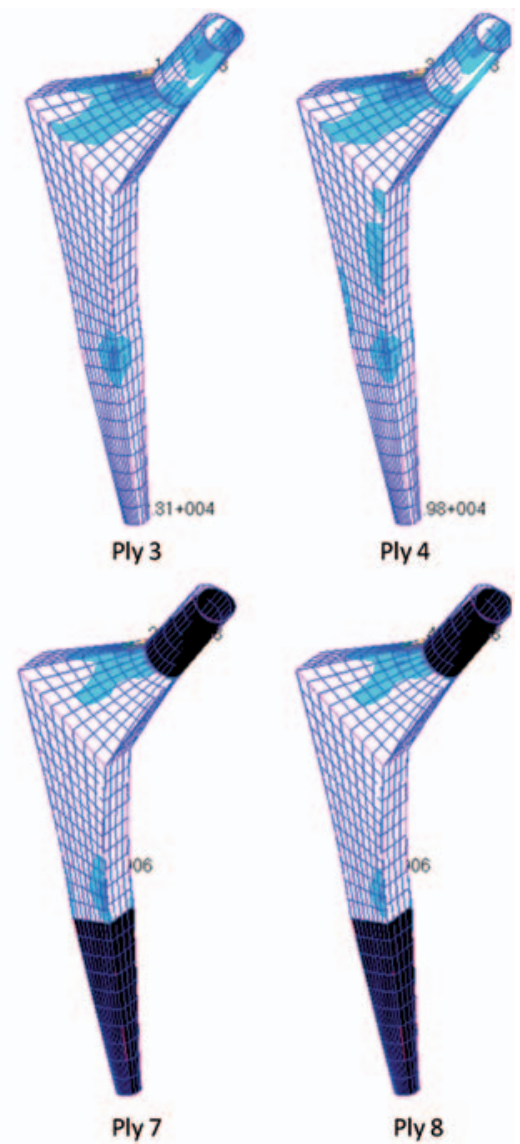

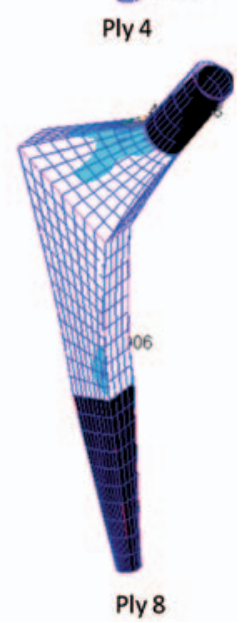

Figure 14. Stress distribution for the component under loading: (a) von Mises stress distribution at ply 1, (b) stress distribution at different plies.

\section{Validation}

A finite element analysis is performed to verify the results achieved in this method. The result of Weight Efficient Approach is plotted with the given dimensions using a CAD tool. A load of $800 \mathrm{lb}(3560 \mathrm{~N})$ is applied to run a finite element analysis. Figure 11 shows the component with created mesh elements and the applied load. In this case the root of the component is assumed to be constrained inside the femur bone to have zero displacement. Figure 12 shows the true scale deformed shape under design loading. From this figure, it can be seen that the maximum deflection is at the tip of the stem as expected.

For convenience of understanding the failure mode, Figure 13 is provided that shows the anticipated deformed shape if the design load is exceeded by a significant amount.

Figure 14(a) shows the von Mises stress distribution in 1st ply, which makes the outer surface of the component. The stresses seem to have tendency to accumulate at Section $\mathrm{A}_{1}-\mathrm{A}_{2}, \mathrm{~B}_{1}-\mathrm{B}_{2}$, and $\mathrm{C}_{1}-\mathrm{C}_{2}$, as defined previously. This agrees with our initial assumption of critical sections for the component.

The result of the finite element analysis shows that maximum stress concentration occurs at Section $A_{1}-A_{2}$. Thus this would be the most critical location for the component shape. Table 9 is created with maximum stress at Section $\mathrm{A}_{1}-\mathrm{A}_{2}$ for each of the eight layers designed for the Weight Efficient Method.

The arithmetic average of these stresses is $238 \mathrm{MPa}$, if cross-sectional areas of different layers are assumed equal. Considering variable cross-sections, the overall stress at Section $\mathrm{A}_{1}-\mathrm{A}_{2}$ is found to be $252 \mathrm{MPa}$. Our design stress at this section is $300 \mathrm{MPa}$, which is met by the results obtained by the analysis. Figure 14(b) shows a comprehensive view of the stress distribution at different layers for easy comparison.

To verify the design, another assumption needs to be satisfied by the obtained results. At Section 4, during defining the case problem, the design strain was considered to be limited to $6.7 \times 10^{-3}$. From the finite element analysis results, the maximum strain is determined to be $1.99 \times 10^{-3}$, which is inside the allowable range. Figure 15(a) and (b) provides a glance of strain 
(a)

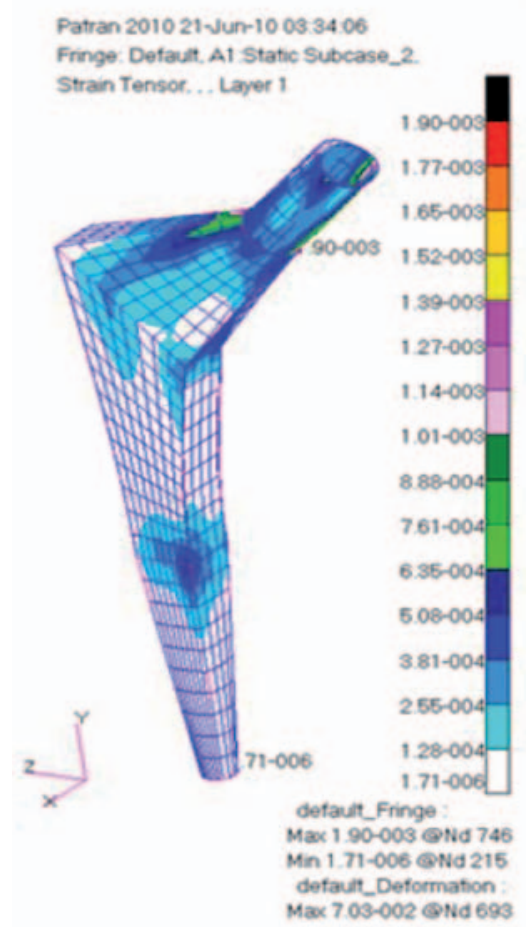

(b)

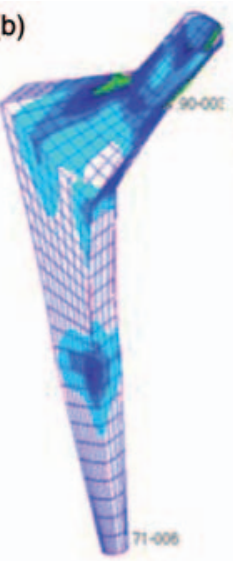

Ply 1

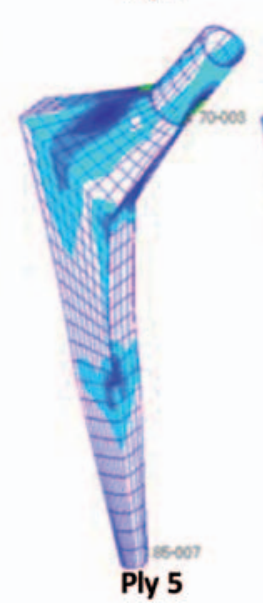

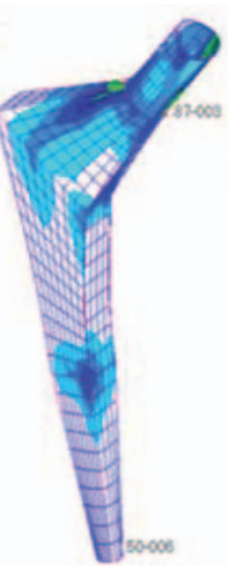

Ply 2

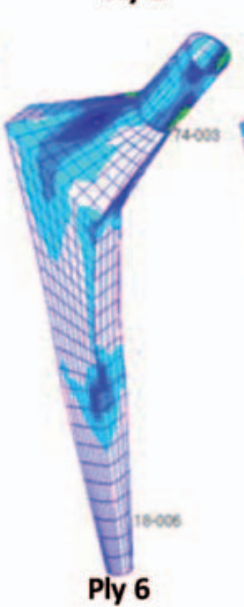

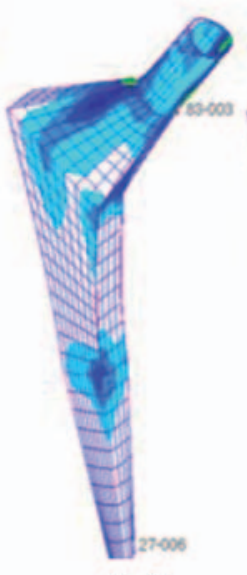

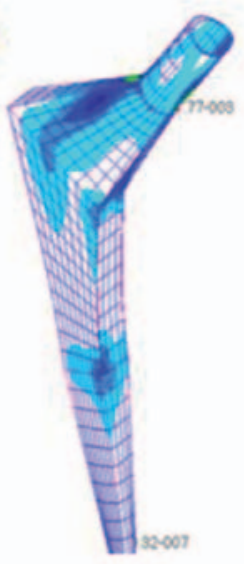

Ply 3

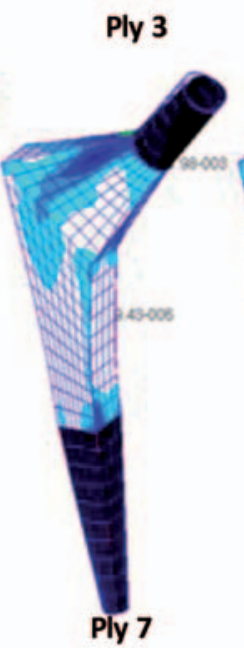

Ply 4

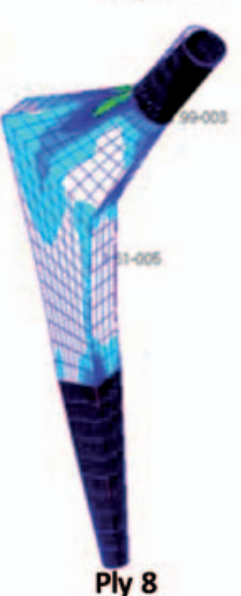

Figure 15. Strain distribution of the component under loading: (a) strain distribution at Ply 1, (b) strain distribution at different Plies.

Table 9. Stresses at section $A_{1}-A_{2}$ at different layers.

\begin{tabular}{lcccccccc}
\hline Plies & Ply $\mathbf{1}$ & Ply 2 & Ply 3 & Ply $\mathbf{4}$ & Ply $\mathbf{5}$ & Ply $\mathbf{6}$ & Ply $\mathbf{7}$ & Ply 8 \\
\hline Stress $(\mathrm{Pa})$ & $1.29 \times 10^{8}$ & $2.08 \times 10^{8}$ & $1.53 \times 10^{8}$ & $3.61 \times 10^{8}$ & $1.40 \times 10^{8}$ & $1.54 \times 10^{8}$ & $2.81 \times 10^{8}$ & $4.75 \times 10^{8}$ \\
\hline
\end{tabular}

distribution at different layers for the design. The Plies 7 and 8 are discontinuous at the stem and root (indicated by dark space).

\section{CONCLUSION}

A new approach, based on shape grammar for design of load-bearing components using composite materials to achieve multiple properties, is presented in this article. Based on the best-fit semi-empirical micro-mechanical models and incorporating lamination theory with these models, this approach selects appropriate composite materials that meet the properties locally and then the laminates are blended throughout the body. The illustrative case study describes the three different approaches for designing the laminates.

The grammatical approach defined in this work combines mechanics (structure and load analysis), composite material selection technique, and shape grammar (that captures design shape from a wide range of shapes), with careful steps of blending variable layer thicknesses to ensure manufacturability of any designed product.

The designs obtained in the case study presented in this article are validated using finite element analysis. Patran (MD Nastran enabled) is used as the tool to model the study and run the analysis. The results of the 
analysis completely agree with the assumptions made for the problem, and validate the reliability of the design under appropriate loading. However, the work presented in this article excludes the selection of an appropriate manufacturing process, which is very crucial in the performance of composite material products.

Thus a possible future work may include an extension of the grammar to analyze different manufacturing processes available so that an appropriate process can be selected to manufacture any particular design. A computer framework can also be developed that will generate shape grammar and design composite material products utilizing the composite material selection tool [32] automatically. Furthermore, costs may also be incorporated with the developed system to obtain more practical and feasible results.

\section{References}

1. Agarwal, M. and Cagan, J. (1997). Shape Grammars and their Languages - A Methodology for Product Design and Product Representation, In: Proceedings of the ASME Design Engineering Technical Conferences, Sacramento, California.

2. Agarwal, M. and Cagan, J. (2000). On the Use of Shape Grammars as Expert Systems for Geometry-Based Engineering Design, Artificial Intelligence for Engineering Design, Analysis and Manufacturing, 14(5): 431-439.

3. Pugliese, M.J. and Cagan, J. (2002). Capturing a Rebel: Modeling the Harley-Davidson Brand through a Motorcycle Shape Grammar, Research in Engineering Design, 13(3): 139-156.

4. McCormacka, J.P., Cagan, J. and Vogel, C.M. (2004). Speaking the Buick Language: Capturing, Understanding, and Exploring Brand Identity with Shape Grammars, Design Studies, 25(1): 1-29.

5. Stiny, G. and Mitchell, W.J. (1978). The Palladian Grammar, Environment and Planning B-Planning and Design, 5(1): 5-18.

6. Koning, H. and Eizenberg, J. (1981). The Language of the Prairie: Frank Lloyd Wright's Prairie Houses, Environment and Planning B-Planning and Design, 8(3): 295-323.

7. Muller, P., Zeng, G., Wonka, P. and Gool, L.V. (2007). Image-based Procedural Modeling of Facades, $A C M$ Transactions on Graphics, 26(3): 85.

8. Stiny, G. (1980). Introduction to Shape and Shape Grammars, Environment and Planning B-Planning and Design, 7(3): 343-351.

9. Stiny, G. (1991). The Algebras of Design, Research in Engineering Design, 2(3): 171-181.

10. Longenecker, S.N. and Fitzhorn, P.A. (1991). A Shape Grammar for Non-Manifold Modeling, Research in Engineering Design, 2(3): 159-170.

11. Reddy, G. and Cagan, J. (1995). An Improved Shape Annealing Algorithm for Truss Topology Generation, Journal of Mechanical Design, 117(2A): 315-322.

12. Shea, K. and Cagan, J. (1997). Innovative Dome Design: Applying Geodesic Patterns with Shape Annealing, Artificial Intelligence for Engineering Design, Analysis and Manufacturing, 11(5): 379-394.
13. Shea, K. and Cagan, J. (1999). Languages and Semantics of Grammatical Discrete Structures, Artificial Intelligence for Engineering Design, Analysis and Manufacturing, 13(4): 241-251.

14. Orsborn, S. and Cagan, J. (2009). Multiagent Shape Grammar Implementation: Automatically Generating Form Concepts According to a Preference Function, Journal of Mechanical Design, 131(12): 121007-1-121007-10.

15. Speller, T.H, Jr., Whitney, D. and Crawley, E. (2007). Using Shape Grammar to Derive Cellular Automata Rule Patterns, Complex Systems, 17(1): 79-102.

16. Agarwal, M., Cagan, J. and Constantine, K.G. (1999). Influencing Generative Design through Continuous Evaluation: Associating Costs with the Coffeemaker Shape Grammar, Artificial Intelligence for Engineering Design, Analysis and Manufacturing, 13(4): 253-275.

17. Lund, E. (2009). Buckling Topology Optimization of Laminated Multi-Material Composite Shell Structures, Composite Structures, 91(2): 158-167.

18. Barbero, E.J. (2008). Finite Element Analysis of Composite Materials, Boca Raton: CRC Press, Taylor \& Francis Group.

19. Eker, B., Akdogan, A. and Vardar, A. (2006). Using of Composite Material in Wind Turbine Blades, Journal of Applied Science, 6(14): 2917-2921.

20. Vallbo, S. (2005). Material Selection Considerations for Polymer Composite Structures in Naval Ship Applications, Journal of Sandwich Structures and Materials, 7(5): 413-429.

21. Rahul, Chakraborty, D. and Dutta, A. (2005). Optimization of FRP Composites against Impact Induced Failure Using Island Model Parallel Genetic Algorithm, Composites Science and Technology, 65(13): 2003-2013.

22. Pedersen, P. (2004). Examples of Density, Orientation, and Shape-Optimal 2D-Design for Stiffness and/or Strength with Orthotropic Materials, Structural and Multidisciplinary Optimization, 26(1-2): 37-49.

23. Gea, H.C. and Luo, J.H. (2004). On the Stress-based and Strain-based Methods for Predicting Optimal Orientation of Orthotropic Materials, Structural and Multidisciplinary Optimization, 26(3-4): 229-234.

24. Ansola, R., Canales, J., Tarrago, J.A. and Rasmussen, J. (2004). Combined Shape and Reinforcement Layout Optimization of Shell Structures, Structural and Multidisciplinary Optimization, 27(4): 219-227.

25. Adams, D.B., Watson, L.T., Gürdal, Z. and AndersonCook, C.M. (2004). Genetic Algorithm Optimization and Blending of Composite Laminates by Locally Reducing Laminate Thickness, Advances in Engineering Software, 35(1): 35-43.

26. Park, C.H., Lee, W.I., Han, W.S. and Vautrin, A. (2002). Weight Minimization of Composite Laminated Plates with Multiple Constraints, Composite Science and Technology, 63(7): 1015-1026.

27. Ghiasi, H., Pasini, D. and Lessard, L. (2009). Pareto Frontier for Simultaneous Structural and Manufacturing Optimization of a Composite Part, Structural and Multidisciplinary Optimization, 40(1-6): 497-511.

28. Ashby, M.F. (1997). Materials Selection: Multiple Constraints and Compound Objectives, In: Ashby, M.F. (ed.), Computerization and Networking of Materials Databases, Vol. 5, STP 1311, pp. 45-62, West Conshohocken, PA, USA: ASTM. 
29. Edwards, K.L., Abel, C.A. and Ashby, M.F. (1994). Optimal Selection of Composite Materials in Mechanical Engineering Design, In: Blain, W.R. et al. (eds.), Proceedings of the 4th International Conference on Computer Aided Design in Composite Material Technology, Southampton, UK, 29 June to 01 July, Computational Mechanics Publications, Southampton, England.

30. Ashby, M.F. (2005). Materials Selection in Mechanical Design, 3rd edn, Oxford: Pergamon Press.

31. Barbero, E.J. (2010). Introduction to Composite Material Design, Philadelphia, PA: CRC Press, Taylor \& Francis Group.

32. Nandi, S. and Siddique, Z. (2009). Composite Material Customization System, In: Proceedings of the ASME 2009 International Design Engineering Technical Conferences \& Computers and Information in Engineering Conference, San Diego, California, 30 August to 02 September, Vol. 2, pp. 861-869, ASME, US.

33. Hamrock, B.J., Schmid, S.R. and Jacobson, B. (2005). Fundamentals of Machine Elements, 2nd edn, New York: McGraw Hill.

34. Herakovich, C.T. (1997). Mechanics of Fibrous Composites, New York: John Wiley \& Sons, Inc.,

35. Park, H.C. and Lakes, R.S. (1986). Cosserat Micromechanics of Human Bone: Strain Redistribution by a Hydration Sensitive Constituent, Journal of Biomechanics, 19(5): 385-397.

36. Adams, D.B., Watson, L.T. and Gurdal, Z. (2003). Optimization and Blending of Composite laminates Using Genetic Algorithms with Migration, Mechanics of Advanced Materials and Structures, 10(3): 183-203.

\section{Soumitra Nandi}

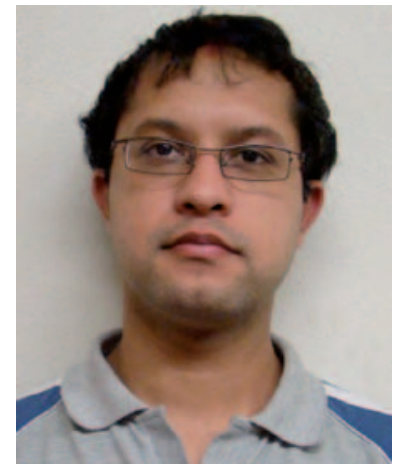

Soumitra Nandi is a doctoral student at the School of Aerospace and Mechanical Engineering, University of Oklahoma. $\mathrm{He}$ has received his undergraduate degree in Mechanical Engineering from Bangladesh University of Engineering and Technology. At present, he is pursuing his research in mass customization of design using laminated composite materials.

\section{Zahed Siddique}

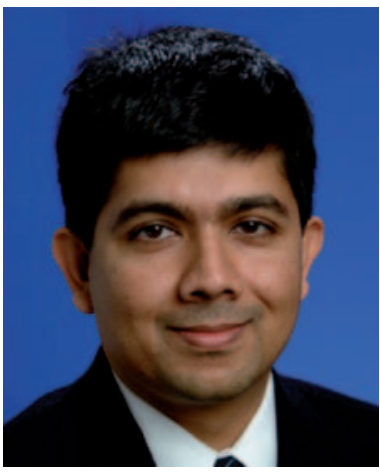

Prof. Zahed Siddique is currently working as an Associate Professor at the School of Aerospace and Mechanical Engineering of University of Oklahoma. His research inters include product family design, collaborative design, design education, and reverse engineering. Dr. Siddique received his Ph.D. in Mechanical Engineering from Georgia Institute of Technology.

\section{Cengiz Altan}

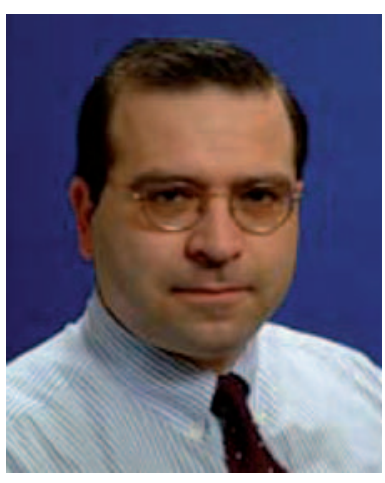

Dr. M.C. Altan is a Presidential Professor at the School of Aerospace and Mechanical Engineering, University of Oklahoma. He has received a Ph.D. degree in Mechanical Engineering from the University of Delaware. He leads the Composite Materials Research Group at the

University of Oklahoma. His primary research interests are in design, manufacturing, and characterization of advanced composite materials and materials development at micro- and nano-scale. 